\title{
Metabolic Adaptations of Skeletal Muscle to Voluntary Wheel Running Exercise in Hypertensive Heart Failure Rats
}

\author{
R. L. SCHULTZ ${ }^{1,2}$, E. L. KULLMAN ${ }^{3,5}$, R. P. WATERS ${ }^{1}$, H. HUANG ${ }^{3}$, J. P. KIRWAN ${ }^{3,4,5,6}$, \\ A. M. GERDES ${ }^{7}$, J. G. SWALLOW ${ }^{1,8}$
}

${ }^{1}$ Department of Biology, University of South Dakota, Vermillion, SD, USA, ${ }^{2}$ University of Sioux Falls, Sioux Falls, SD, USA, ${ }^{3}$ Department of Pathobiology, Lerner Research Institute, Cleveland Clinic, Cleveland, OH, USA, ${ }^{4}$ Metabolic Translational Research Center, Endocrinology and Metabolism Institute, Cleveland Clinic, Cleveland, OH, USA, ${ }^{5}$ Department of Nutrition, Case Western Reserve University, School of Medicine, Cleveland, OH, USA, ${ }^{6}$ Department of Physiology, Case Western Reserve University, School of Medicine, Cleveland, OH, USA, ${ }^{7}$ Department of Biological Sciences, New York College of Osteopathic Medicine at New York Institute of Technology, Old Westbury, NY, USA, ${ }^{8}$ Department of Integrative Biology, University of Colorado Denver, Denver, CO, USA

Received February 3, 2012

Accepted February 21, 2013

On-line April 16, 2013

\section{Summary}

The Spontaneously Hypertensive Heart Failure (SHHF) rat mimics the human progression of hypertension from hypertrophy to heart failure. However, it is unknown whether SHHF animals can exercise at sufficient levels to observe beneficial biochemical adaptations in skeletal muscle. Thirty-seven female SHHF and Wistar-Furth (WF) rats were randomized to sedentary (SHHFsed and WFsed) and exercise groups (SHHFex and WFex). The exercise groups had access to running wheels from 6-22 months of age. Hindlimb muscles were obtained for metabolic measures that included mitochondrial enzyme function and expression, and glycogen utilization. The SHHFex rats ran a greater distance and duration as compared to the WFex rats $(P<0.05)$, but the WFex rats ran at a faster speed $(P<0.05)$. Skeletal muscle citrate synthase and $\beta$-hydroxyacyl-CoA dehydrogenase enzyme activity was not altered in the SHHFex group, but was increased $(P<0.05)$ in the WFex animals. Citrate synthase protein and gene expression were unchanged in SHHFex animals, but were increased in WFex rats $(P<0.05)$. In the WFex animals muscle glycogen was significantly depleted after exercise $(P<0.05)$, but not in the SHHFex group. We conclude that despite robust amounts of aerobic activity, voluntary wheel running exercise was not sufficiently intense to improve the oxidative capacity of skeletal muscle in adult SHHF animals, indicating an inability to compensate for declining heart function by improving peripheral oxidative adaptations in the skeletal muscle.

\section{Key words}

SHHF • Wheel running • Voluntary exercise $\bullet$ Heart failure

\section{Corresponding author}

J. G. Swallow, Department of Integrative Biology, University of Colorado Denver, Campus Box 171, POB 173364, Denver, CO 80217-3364, USA. Fax: 303-556-4352. E-mail: john.swallow@ucdenver.edu

\section{Introduction}

Voluntary wheel running (VWR) is an effective exercise model because, given access to running wheels, rodents will run many kilometers per day through a series of short relatively high-intensity bouts (Eikelboom and Mills 1988, Rodnick et al. 1989, Swallow et al. 1998a, De Bono et al. 2006). As an exercise modality, VWR is less stressful because it requires minimal experimental handling and, therefore, does not disrupt the normal diurnal pattern of rodent activity. VWR elicits a variety of physiological modifications including decreases in body mass and body fat (Swallow et al. 1999, 2001, 
Dumke et al. 2001), increases in maximal $\mathrm{O}_{2}$ consumption, (Lambert and Noakes 1990, Swallow et al. 1998b), and metabolic alteration of cardiac and skeletal muscles (Rodnick et al. 1989, Ishihara et al. 1991, HouleLeroy et al. 2000, Allen et al. 2001, Dumke et al. 2001, Harrison et al. 2002). Furthermore, VWR also reduces risk factors for heart failure (HF), including lowering resting systolic blood pressure as shown in spontaneously hypertensive rats (Overton et al. 1986, Kinney LaPier and Rodnick 2001). This is consistent with evidence of low stress exercise in humans inducing beneficial cardiovascular adaptations. As a consequence, low stress exercise is now recommended for HF patients (Aronow 2003, Pina et al. 2003, Smart and Marwick 2004).

The Spontaneously Hypertensive Heart Failure (SHHF) rat provides a model that mimics human progression of hypertension from cardiac hypertrophy to heart failure. Animal studies examining the effectiveness of regular exercise training on cardiac remodeling and ventricular function in both the healthy heart and in various models of hypertension and heart failure have used VWR (Allen et al. 2001, Natali et al. 2002, Konhilas et al. 2005, 2006). Most report a beneficial effect of exercise, but one study using a severe transverse aortic constriction model found that exercise accelerated cardiac dysfunction (van Deel et al. 2011). Similarly, we have previously reported that 16 months of exercise in SHHF rodents resulted in greater left ventricle (LV) chamber dilation, worsening of LV function, and accelerated signs of heart failure compared to sedentary controls (Schultz et al. 2007).

The compensatory effects of endurance exercise on peripheral muscular oxidative adaptations and the progression to heart failure are important in the context of potential treatments for heart failure. However, previous studies have shown that the derangement of skeletal muscle oxidative metabolism associated with heart failure can be prevented, or normalized, with regular endurance exercise and this also alleviated many of the symptoms associated with heart failure (reviewed in VenturaClapier et al. 2007). As such, we measured markers of skeletal muscle oxidative metabolism after providing running wheels to female SHHF rats from the ages of six months until 22 months. To our knowledge, it is unknown whether SHHF rats can exercise at a sufficient stimulus to observe metabolic adaptations in skeletal muscle, in the presence of progressive heart failure. Thus, the purpose of this study was to determine the potential effectiveness of VWR in compensating for heart failure through beneficial changes in muscle oxidative capacity.

\section{Methods}

\section{Experimental design}

Lean female SHHF rats were purchased from Charles River Laboratories (Indianapolis, IN). Agematched female Wistar-Furth rats (WF; Charles River Laboratories; Wilmington, MA) served as both normotensive and exercise controls. Eleven SHHF and $7 \mathrm{WF}$ female rats were housed individually in clear plastic Nalge $\mathrm{T}^{\mathrm{TM}}$ cages (43"x 27"x 15") with cedar bedding and wire lids. Stainless steel running wheels (Nalgene Activity Wheels for Rodents, Fisher Scientific) were placed inside their cages beginning at six months of age. Teklad Rodent Diet (8604) and water were available ad libitum. Wheel-running behavior of the exercise trained SHHF (SHHFex) and WF (WFex) rats was monitored from 6 to 22 months of age. Heart function was also assessed in all rodents and has been reported previously (Schultz et al. 2007). Rats were maintained in the same environment including temperature and humidity on a 12:12 dark:light cycle (dark 0600-1800) using an automatic timer. All procedures in this study were approved by the University of South Dakota Animal Care and Use Committee and followed Institutional guidelines for animals.

\section{Wheel running quantification}

Running wheels were connected to a Minimitter ${ }^{\mathrm{TM}}$ system using a magnetic sensor to record wheel rotations. This system was interfaced with a computer, and recorded using VitalView ${ }^{\mathrm{TM}}$ software at one-minute intervals $24 \mathrm{~h}$ /day during months 3-9, 12-13, and 15 of the study, which corresponded with ages 9-15, 18-19, and 21 months. The circumference of the running wheel was $1.08 \mathrm{~m}$. Therefore, to obtain the total number of meters run by each animal the number of revolutions of the wheel was multiplied by 1.08. VitalView ${ }^{\mathrm{TM}}$ software (Mini Mitter Co., Inc., Bend, OR) was set to store the number of revolutions per minute and to ascertain the total amount of running time and distance.

\section{mRNA expression}

Total mRNA was isolated from $\sim 20 \mathrm{mg}$ of rat hindlimb mixed skeletal muscle using TriReagent (Molecular Research Center, Cincinnati, $\mathrm{OH}$ ), which is based on the guanidine thiocyanate method. Muscle samples were homogenized with a glass homogenizer on 
ice in $1 \mathrm{ml}$ of ice-cold TriReagent. RNA was solubilized in RNase-free $\mathrm{H}_{2} \mathrm{O}$ and quantitated by measuring the absorbance at $260 \mathrm{~nm}$. Purity was verified by an absorbance (A) 260/280 ratio greater than 1.6 (normally 1.8-2.0). First-strand cDNA was synthesized from 2 ug of total RNA using RETROscript reverse transcriptase (RT, Ambion, Austin, TX). mRNA expression for genes of interest was measured in duplicate with a Stratagene MX3000P real-time PCR machine using SYBR green with ROX as a reference dye (Stratagene, La Jolla, CA). A primer pair was designed against citrate synthase (CS) (NM-130755.1) (forward 5'-CCGTGCTCATGGACTT GGGCCTT-3'; reverse 5'-CCCCTGGCCCAACGTAGA TGCTC-3') and $\beta$-hydroxyacyl-CoA dehydrogenase ( $\beta$-HAD) (NM-130826.2) (forward 5'-CCAAACTAA AGCCTGCATTCATC-3'; reverse 5'-CGCCATCAGT CAGGAAAGAAG-3'). GAPDH (NM-017008.3) was used as the housekeeping gene (Integrated DNA Technologies, Coralville, IA) (Siu et al. 2003). The PCR parameters included: initial denaturing at $95^{\circ} \mathrm{C}$ for $10 \mathrm{~min}$ to activate the DNA polymerase followed by 40 cycles of $30 \mathrm{~s}$ at $95^{\circ} \mathrm{C}, 60 \mathrm{~s}$ at an annealing temperature of $55^{\circ} \mathrm{C}$ ), and $30 \mathrm{~s}$ at $72{ }^{\circ} \mathrm{C}$ for acquisition of fluorescence signal. The expression levels were calculated by the delta-delta threshold cycle $(\mathrm{Ct})$ method (Livak and Schmittgen 2001).

\section{Protein expression}

Citrate synthase and $\beta$-HAD protein expression were determined in skeletal muscle samples using Western blot analysis. Frozen muscle was homogenized with a glass homogenizer in freshly prepared ice-cold buffer $(150 \mathrm{mM}$ Hepes, $150 \mathrm{mM} \mathrm{NaCl}, 20 \mathrm{mM}$ betaglycerophosphate, $10 \mathrm{mM}$ EDTA, $1 \%$ NP-40, $10 \%$ glycerol, $1 \mathrm{mM} \mathrm{MgCl} 2,1 \mathrm{mM} \mathrm{CaCl} 2,20 \mathrm{mM} \mathrm{Na}_{4} \mathrm{P}_{2} \mathrm{O}_{7}$, $10 \mathrm{mM} \mathrm{NaF}, 2 \mathrm{mM}$ sodium orthovanadate, $2 \mathrm{mM}$ PMSF and $5 \mathrm{ul} / \mathrm{ml}$ of protease inhibitor cocktail (P8340, Sigma, St. Louis, MO, 10 ul of buffer per mg of muscle). The homogenate was centrifuged for $10 \mathrm{~min}$ at $12,000 \mathrm{rpm}$ at $4{ }^{\circ} \mathrm{C}$. Protein concentration was quantified using a commercial BCA protein assay kit (Pierce, Rockford, IL). Aliquots of homogenate were solubilized in lithium dodecyl sulfate (LDS) sample buffer with a final concentration of $1 \mathrm{ug} / \mathrm{ul}$, and $20 \mathrm{ug}$ of protein was separated by $12 \%$ SDS-PAGE. After electrophoresis, the proteins were electro-transferred to a nitrocellulose membrane (Bio-Rad, Hercules, CA). Membranes were blocked in $1 \%$ TBST (10 mM Tris, $100 \mathrm{mM} \mathrm{NaCl}$, and $0.01 \%$ Tween, $\mathrm{pH} 7.5$ ) containing $5 \%$ nonfat milk overnight at $4{ }^{\circ} \mathrm{C}$, washed with TBST for $15 \mathrm{~min}$, and incubated with primary antibody (1:5000 dilution) for one hour at room temperature (Diagnostic International, San Antonio, TX). The membranes were washed 5 times for $5 \mathrm{~min}$ each wash before incubation with a secondary anti-rabbit IgG antibody (1:10,000; Diagnostic International, San Antonio, TX) for one hour at room temperature. The membranes were washed with TBST again and subjected to enhanced chemiluminescence (Amersham Biosciences, Piscataway, NJ). The membranes were subsequently stripped with $0.5 \mathrm{M}$ $\mathrm{NaOH}$ for 15 min at room temperature and reprobed with beta-actin primary antibody $(1: 1000)$ for one hour at room temperature (Sigma, St Louis, MO). The membrane was washed several times with TBST before incubation with a secondary anti-mouse IgG antibody (1:10,000; Sigma, St Louis, MO). The results were quantified by scanning densitometry (Kodak, IS 4000R, Rochester, $\mathrm{NY}$ ).

\section{Mitochondrial enzyme activities \\ Citrate synthase activity}

Spectrophotometric analysis of citrate synthase activity was conducted by the method of Srere (Srere and John 1969) as previously described (Kirwan et al. 1990). Muscle was homogenized in potassium phosphate buffer ( $50 \mathrm{mM} \mathrm{KH}_{2} \mathrm{PO}_{4}, 1 \mathrm{mM}$ EDTA, $2 \mathrm{mM} \mathrm{MgCl}_{2}$ ) to create a $5 \%$ homogenate. A 5 ul sample of homogenate was added to $815 \mathrm{ul}$ of $\mathrm{ddH}_{2} \mathrm{O}, 30 \mathrm{ul}$ of $10 \mathrm{mM}$ Acetyl CoA, and $100 \mathrm{ul}$ of $1 \mathrm{mM}$ DNTB. The absorption at $412 \mathrm{~nm}$ was followed for $3 \mathrm{~min}$ to measure possible acetyl-CoA deacylase activity. The reaction was started by adding $50 \mathrm{ul}$ of $10 \mathrm{mM}$ oxaloacetate. Linear rates were obtained for at least $3 \mathrm{~min}$ at $37^{\circ} \mathrm{C}$. Protein extracts of the homogenates were quantified in triplicate using bicinchoninic acid reagent (Pierce, Rockford, IL) and bovine serum albumin standards. The CS activity was then normalized to the total protein content and is reported as nanomoles per milligram protein per minute.

\section{$\beta$-hydroxyacyl-CoA dehydrogenase ( $\beta$-HAD) activity}

The muscle tissue $(\sim 10 \mathrm{mg})$ was homogenized in $100 \mathrm{vol} / \mathrm{wt}$ of a $100 \mathrm{mM}$ potassium phosphate buffer for measurement of $\beta$-HAD activity. Total muscle activity was measured in Tris-HCL buffer $(50 \mathrm{mM}$ Tris-HCL, $2 \mathrm{mM}$ EDTA, and $250 \mathrm{uM} \mathrm{NADH}, \mathrm{pH} 7.0$ ) and $0.04 \%$ Triton-X. The reaction was started by addition of $100 \mathrm{uM}$ of acetoacetyl CoA. The activity was assayed spectrophotometrically over 2 min at $37^{\circ} \mathrm{C}$ by measuring 
the disappearance of NADH at $340 \mathrm{~nm}$ (Essen et al. 1975).

\section{Skeletal muscle glycogen content}

Tissue glycogen was measured in perchloric acid extracts using the amyloglucosidase method (Passonneau and Lauderdale 1974).

\section{Statistical analyses}

All data are presented as means \pm SE. Changes in wheel running behavior over time and group differences in muscle gene and protein expression, protein activity, and glycogen were assessed using twoway ANOVA. The Bonferroni post hoc test was used to examine statistically significant differences. Student's t-tests were used to determine differences in wheel running averages between groups. Results were considered significant when $P<0.05$.

\section{Results}

Body weight did not differ between any of the groups at 22 months of age (SHHFsed $=292 \pm 18 \mathrm{~g}$, SHHFex $=298 \pm 18 \mathrm{~g}, \mathrm{WFsed}=283 \pm 28 \mathrm{~g}, \mathrm{WFex}=308 \pm 18 \mathrm{~g}$ ). The SHHFex rats ran an average of $7.5 \pm 0.9 \mathrm{~km} /$ day, $339 \pm 46 \mathrm{~min} /$ day, and $22.1 \pm 2.6 \mathrm{~m} / \mathrm{min}$. In comparison, the WFex rats ran an average of $5.6 \pm 2.0 \mathrm{~km} / \mathrm{day}, 201 \pm 29$ $\mathrm{min} /$ day, and $31.6 \pm 3.1 \mathrm{~m} / \mathrm{min}$. Statistical analysis revealed that SHHFex averaged a greater distance per day $(P<0.05)$ and time per day $(P<0.05)$ than WFex, but the WFex ran at a significantly higher intensity $(P<0.05)$.

\section{Skeletal muscle gene and protein expression}

Citrate synthase mRNA levels were similar for the WFsed and SHHFsed groups. Increased physical activity stimulated an increase in citrate synthase gene expression in the WFex animals compared to the control WFsed group $(P<0.05)$ (Fig. 1A). In contrast, the SHHFex group did not show an increase in mRNA levels compared with SHHFsed. Citrate synthase protein expression was also increased in the WFex group compared to the WFsed animals $(P<0.05$, Fig. 1B). Further, protein expression in the SHHFex group was significantly lower $(P<0.05)$ than the SHHFsed, or the WFex groups.

$\beta$-HAD gene expression was higher in the WFex group than either the WFsed or the SHHFex groups $(P<0.05)$. A similar pattern of expression was found for $\beta$-HAD protein and the WFex group had increased
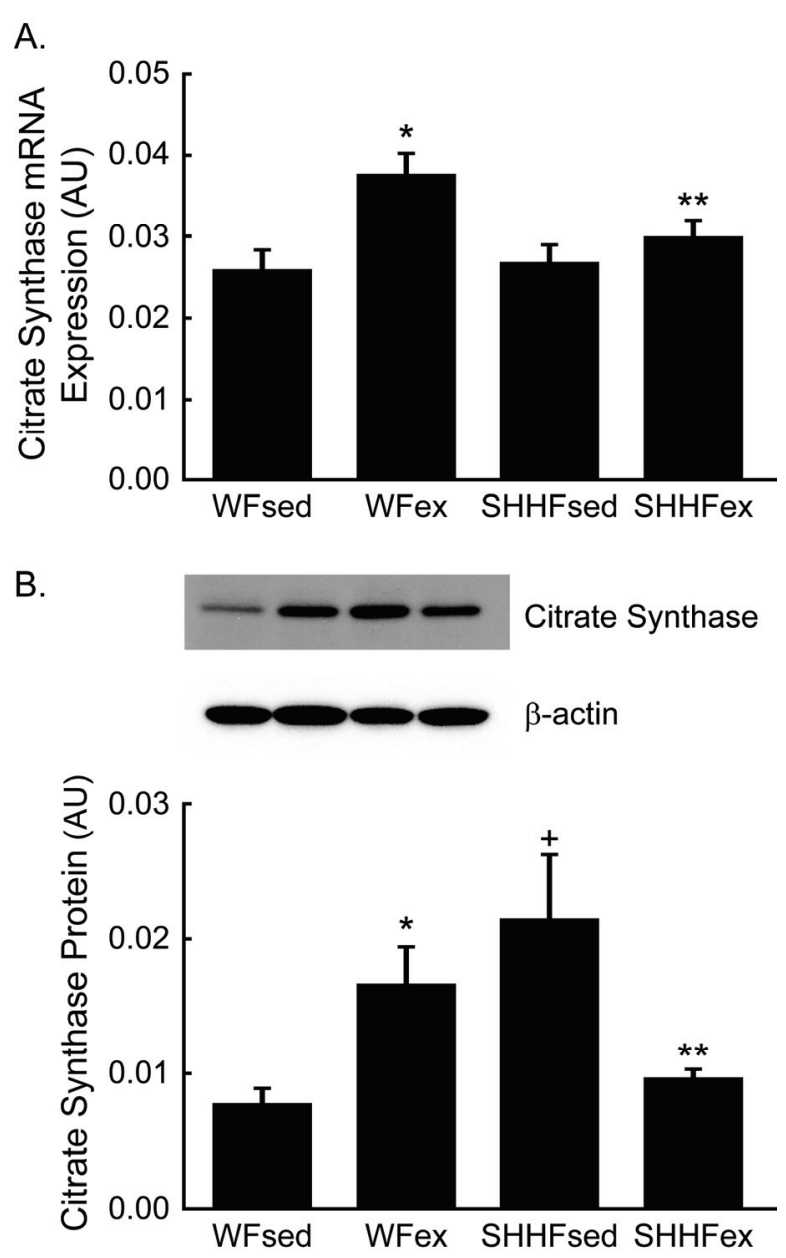

Fig. 1. A. Representative $q R T-P C R$ results for citrate synthase in skeletal muscle from WFsed $(n=9)$, WFex $(n=5)$, SHHFsed $(n=9)$, and SHHFex $(n=11)$ groups. Normalized data are presented as means $\pm \mathrm{SE}$. $* P<0.05$, WFex group is significantly increased compared to WFsed. $* * P<0.05$, SHHFex group is significantly lower than WFex. B. Citrate synthase protein expression in skeletal muscle of WFsed $(n=9)$, WFex $(n=5)$, SHHFsed $(n=11)$, and SHHFex $(n=10)$ groups. Normalized data are presented as means $\pm \mathrm{SE} ; * P<0.05$, WFex significantly increased compared to control WFsed. ${ }^{+} P<0.05$, SHHFsed group is significantly greater than SHHFex. $* * P<0.05$, SHHFex group is significantly lower than WFex.

expression compared to the WFsed and SHHFex controls $(P<0.05)$, while there was no difference between the SHHFsed and SHHFex groups (Fig. 2).

\section{Skeletal muscle citrate synthase and $\beta$-HAD activity}

Citrate synthase enzyme activity was not different in the WFsed group compared with the SHHFsed group. Exercise increased in citrate synthase activity in the WFex animals when compared to the WFsed controls $(P<0.05)$. In contrast, SHHFex rats did not show an increase in citrate synthase activity compared to the SHHFsed control group. Further, citrate synthase activity in SHHFex rats exposed to wheel 
A.

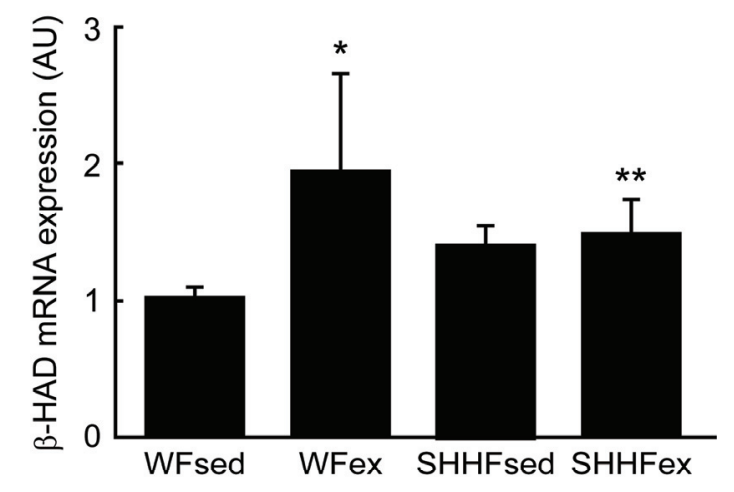

B.
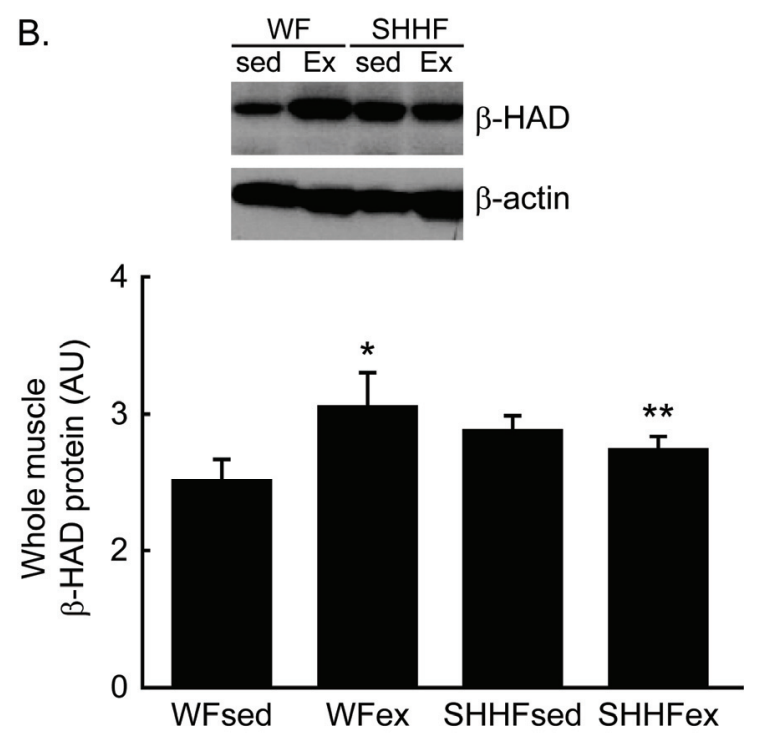

Fig. 2. A. $q R T-P C R$ results for $\beta-H A D$ in skeletal muscle from WFsed $(n=10)$, WFex $(n=5)$, SHHFsed $(n=10)$, and SHHFex $(n=9)$ groups. Normalized data are presented as means $\pm S E$. ${ }^{*} P<0.05$, WFex group is significantly higher than WFsed. $* * P<0.05$, SHHFex group is significantly lower than WFex. B. $\beta$-HAD protein expression in skeletal muscle of WFsed $(n=10)$, WFex $(n=4)$, SHHFsed $(n=10)$, and SHHFex $(n=9)$ groups. Normalized data are presented as means $\pm \mathrm{SE}$. $* P<0.05$, the WFex group was significantly increased compared to WFsed. $* * P<0.05$, SHHFex group is significantly lower than WFex.

running was lower compared with the WFex group $(P<0.05)$ (Fig. 3A).

Enzyme activity of $\beta$-HAD, which is a key enzyme of $\beta$-oxidation in skeletal muscle was also used to probe for changes in mitochondrial function. Similar to data for citrate synthase activity, $\beta$-HAD activity was greater in the WFex animals compared to WFsed and SHHFex $(P<0.05)$ (Fig. 3B).

\section{Skeletal muscle glycogen content}

Muscle glycogen concentrations were measured in samples obtained after the animals had access to the running wheels. Consequently, the active WFex animals had reduced muscle glycogen $(45.0 \pm 7.5 \mu \mathrm{mol} / \mathrm{g} w w t)$
A.
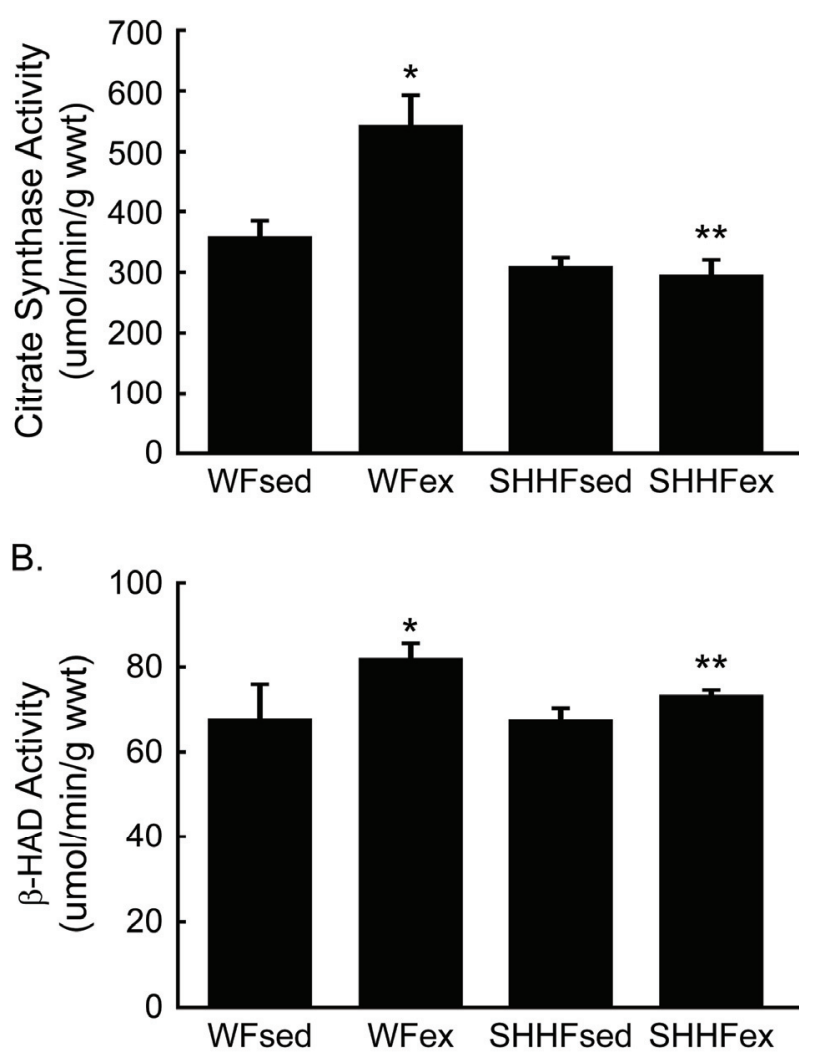

Fig. 3. A. Citrate synthase activity in skeletal muscle of the WFsed $(n=8)$, WFex $(n=5)$, SHHFsed $(n=10)$ and SHHFex $(n=8)$ groups. $* P<0.05$, the WFex group was significantly increased compared to the WFsed group. $* * P<0.05$, SHHFex group is significantly lower than WFex. B. Enzyme activity of $\beta-H A D$ in skeletal muscle of WFsed $(n=8)$, WFex $(n=5)$, SHHFsed $(n=10)$ and SHHFex $(n=10)$ groups. Data are presented as means \pm SE. $* P<0.05$, WFex group was significantly increased compared to the WFsed. $* * P<0.05$, SHHFex group is significantly lower than WFex.

compared to the sedentary WFsed group (90.2 \pm 7.9 $\mu \mathrm{mol} / \mathrm{g}$ wwt; $P<0.05$ ) (Fig. 4). Glycogen levels in the SHHFsed group $(74.6 \pm 8.3 \mu \mathrm{mol} / \mathrm{g}$ wwt $)$ were not different from the WFsed group. Importantly, the SHHFex group $(69.1 \pm 3.7 \mu \mathrm{mol} / \mathrm{g} \quad \mathrm{wwt})$ did not experience any reduction in muscle glycogen compared to SHHFsed despite exposure to the running wheel.

\section{Discussion}

This is the first study to examine the effect of VWR on muscle oxidative enzyme adaptations in a rat model of heart failure. Our results indicate that the SHHF rat will run at distances and durations similar to or greater than other species and strains of rodents (Rodnick et al. 1989, Jonsdottir et al. 1998, Kingwell et al. 1998, Allen et al. 2001, Kinney LaPier and Rodnick 2001, Burghardt et al. 2004, Beatty et al. 2005, Nelson et al. 2005, 


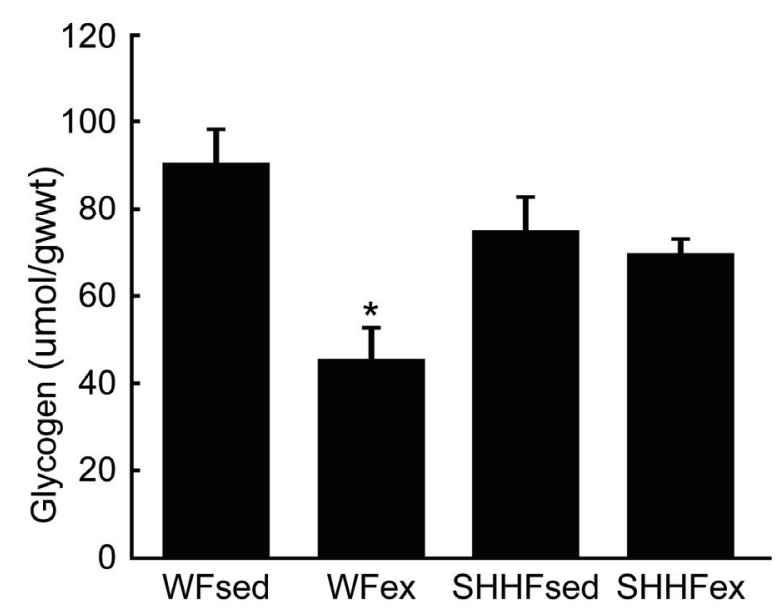

Fig. 4. Glycogen content in WFsed $(n=9)$, WFex $(n=5)$, SHHFsed $(\mathrm{n}=10)$, and SHHFex $(\mathrm{n}=11)$ groups. $* P<0.05$, WFex was significantly lower than WFsed.

Konhilas et al. 2006). The SHHFex rats in this study tended to maintain their VWR patterns throughout the study, despite the fact that many had already developed or were transitioning to heart failure (previously reported in Schultz et al. 2007). However, in contrast to healthy rats this mode of exercise failed to improve peripheral muscular adaptations in SHHF animals.

Previously, it has been shown that heart failure causes exercise intolerance which leads to subsequent declines in muscle oxidative enzyme activity (Pfeifer $e t$ al. 2001). It is therefore likely that the progression of heart failure in our rats limited their ability to achieve and sustain higher intensity exercise, thus failing to provide an adequate stimulus for oxidative adaptations. Although the SHHFex rats exercised for a longer duration per day on average than the WFex rats, the WFex rats exercised at a higher intensity. This was further evidenced by the reduction of muscle glycogen in the WFex rats, while no such observation was made in SHHFex rats. When considering appropriate stimuli for the increase in abundance and activity of the oxidative enzymes, citrate syntase and $\beta$-HAD, short bouts of high-intensity exercise have been shown to be comparable to the effectiveness of the traditional model of training mode of moderateintensity, long-duration continuous training in rodents (Terada et al. 2004, Bexfield et al. 2009) and humans alike (den Hoed et al. 2008, Green et al. 2008). It would appear that the exercise performed by the control rats was of sufficient intensity to cause increased activation of the oxidative enzymes citrate synthase and $\beta-\mathrm{HAD}$, whereas the lower-intensity exercise of the SHHFex rats was inadequate.

It was somewhat surprising that muscle oxidative enzyme content and activity was not improved relative to the SHHFsed despite the robust accumulation of physical activity. Several factors, such as gender and mode of exercise may have had an impact on peripheral and central outcomes of the SHHF rats exposed to VWR. Additionally, it is unknown what effect alterations in circulating endothelin-1 and angiotensin II may have had on oxidative adaptations, considering both of these markers have been shown to be elevated in heart failure, and both are inhibitors of PGC-1 $\alpha$ (Garnier et al. 2009). However, a recent meta-analysis of exercise in the SHR model (Schluter et al. 2010) found that the age at the start of an exercise intervention has a considerable impact on the physiological benefits of the exercise in a disease model. We started our exercise intervention at 6 months of age, which was well into the progression of heart failure as evidenced by increased wall thickness compared to the WF (previously reported in Schultz et al. 2007). Relative to most other rodent models of exercise, this is a fairly advanced age. Emter and colleagues (2005) were able to delay the progression of heart failure in SHHF rats, but rodents began exercise at a much younger age and before the onset of pathological changes (Emter et al. 2005). Another study employing voluntary wheel running in the hypertrophic cardiomyopathy (HCM) mouse model found prevention and reversal of heart changes in exercised mice, and these benefits were greatest when exercise was initiated before the disease was established (Konhilas et al. 2006). Furthermore, these authors reported that animals beginning exercise at 6 months of age failed to prevent the progression of fibrosis and had the greatest increase in cardiac mass. Thus, it appears that in this SHHF rodent model, exercise may only be beneficial before the onset of pathological changes related to heart failure.

In conclusion, this study demonstrates that SHHF rats will engage in VWR at durations and distances greater than other strains and species, but fail to show beneficial oxidative adaptations in skeletal muscle. The likely reason for this is the significantly lower exercise intensity as a result of the progression of heart failure with subsequent exercise intolerance, thereby preventing sufficient stimulus for oxidative muscle adaptations. One major influencing factor appears to have been the advanced age and progression of disease at the initiation of the exercise intervention. We conclude that it is best to begin exercise early to delay the progression of heart failure and to promote beneficial muscular oxidative adaptations. 


\section{Conflict of Interest}

There is no conflict of interest.

\section{Acknowledgements}

This work was supported by grant HL62459 from the National Institutes of Health-Heart, Lung, and Blood Institute, grants P20 RR017662 and P20 RR15576 from the National Institutes of Health-National Center for
Research Resources, grants from NSF (IOB-0448060), NSF EPSCoR in South Dakota (0091948), and from the USDMS through their Center of Biomedical Research Excellence (COBRE - NIH P20 RR15567) to JGS. ESL was supported by NIH grant T32DK007319. The authors would also like to acknowledge the technical contribution of Francis Chan for the muscle enzyme analyses.

\section{References}

ALLEN D L, HARRISON BC, MAASS A, BELL ML, BYRNES WC, LEINWAND LA: Cardiac and skeletal muscle adaptations to voluntary wheel running in the mouse. J Appl Physiol 90: 1900-1908, 2001.

ARONOW WS: Epidemiology, pathophysiology, prognosis, and treatment of systolic and diastolic heart failure in elderly patients. Heart Dis 5: 279-294, 2003.

BEATTY JA, KRAMER JM, PLOWEY ED, WALDROP TG: Physical exercise decreases neuronal activity in the posterior hypothalamic area of spontaneously hypertensive rats. $J$ Appl Physiol 98: 572-578, 2005.

BEXFIELD NA, PARCELL AC, NELSON WB, FOOTE KM, MACK GW: Adaptations to high-intensity intermittent exercise in rodents. $J$ Appl Physiol 107: 749-754, 2009.

BURGHARDT PR, FULK LJ, HAND GA, WILSON MA: The effects of chronic treadmill and wheel running on behavior in rats. Brain Res 1019: 84-96, 2004.

DE BONO JP, ADLAM D, PATERSON DJ, CHANNON KM: Novel quantitative phenotypes of exercise training in mouse models. Am J Physiol Regul Integr Comp Physiol 290: R926-R934, 2006.

DEN HOED M, HESSELINK MK, VAN KRANENBURG GP, WESTERTERP KR: Habitual physical activity in daily life correlates positively with markers for mitochondrial capacity. J Appl Physiol 105: 561-568, 2008.

DUMKE CL, RHODES JS, GARLAND T JR, MASLOWSKI E, SWALLOW JG, WETTER AC, CARTEE GD: Genetic selection of mice for high voluntary wheel running: effect on skeletal muscle glucose uptake. $J$ Appl Physiol 91: 1289-1297, 2001.

EIKELBOOM R, MILLS R: A microanalysis of wheel running in male and female rats. Physiol Behav 43: 625-630, 1988.

EMTER CA, MCCUNE SA, SPARAGNA GC, RADIN MJ, MOORE RL: Low-intensity exercise training delays onset of decompensated heart failure in spontaneously hypertensive heart failure rats. Am J Physiol Heart Circ Physiol 289: H2030- H2038, 2005.

ESSEN B, JANSSON E, HENRIKSSON J, TAYLOR AW, SALTIN B: Metabolic characteristics of fibre types in human skeletal muscle. Acta Physiol Scand 95: 153-165, 1975.

GARNIER A, ZOLL J, FORTIN D, N'GUESSAN B, LEFEBVRE F, GENY B, METTAUER B, VEKSLER V, VENTURA-CLAPIER R: Control by circulating factors of mitochondrial function and transcription cascade in heart failure: a role for endothelin-1 and angiotensin II. Circ Heart Fail 2: 342-350, 2009.

GREEN HJ, BOMBARDIER EB, DUHAMEL TA, HOLLOWAY GP, TUPLING AR, OUYANG J: Acute responses in muscle mitochondrial and cytosolic enzyme activities during heavy intermittent exercise. $J$ Appl Physiol 104: 931-937, 2008.

HARRISON BC, BELL ML, ALLEN DL, BYRNES WC, LEINWAND LA: Skeletal muscle adaptations in response to voluntary wheel running in myosin heavy chain null mice. J Appl Physiol 92: 313-322, 2002.

HOULE-LEROY P, GARLAND T JR, SWALLOW JG, GUDERLEY H: Effects of voluntary activity and genetic selection on muscle metabolic capacities in house mice Mus domesticus. J Appl Physiol 89: 1608-1616, 2000.

ISHIHARA A, INOUE N, KATSUTA S: The relationship of voluntary running to fibre type composition, fibre area and capillary supply in rat soleus and plantaris muscles. Eur J Appl Physiol Occup Physiol 62: 211-215, 1991. 
JONSDOTTIR IH, JUNGERSTEN L, JOHANSSON C, WENNMALM A, THOREN P, HOFFMANN P: Increase in nitric oxide formation after chronic voluntary exercise in spontaneously hypertensive rats. Acta Physiol Scand 162: 149-153, 1998.

KINGWELL BA, ARNOLD PJ, JENNINGS GL, DART AM: The effects of voluntary running on cardiac mass and aortic compliance in Wistar-Kyoto and spontaneously hypertensive rats. J Hypertens 16: 181-185, 1998.

KINNEY LAPIER TL, RODNICK KJ: Effects of aerobic exercise on energy metabolism in the hypertensive rat heart. Phys Ther 81: 1006-1017, 2001.

KIRWAN JP, COSTILL DL, FLYNN MG, NEUFER PD, FINK WJ, MORSE WM: Effects of increased training volume on the oxidative capacity, glycogen content and tension development of rat skeletal muscle. Int $J$ Sports Med 11: 479-483, 1990.

KONHILAS JP, WATSON PA, MAASS A, BOUCEK DM, HORN T, STAUFFER BL, LUCKEY SW, ROSENBERG P, LEINWAND LA: Exercise can prevent and reverse the severity of hypertrophic cardiomyopathy. Circ Res 98: 540-548, 2006.

KONHILAS JP, WIDEGREN U, ALLEN DL, PAUL AC, CLEARY A, LEINWAND LA: Loaded wheel running and muscle adaptation in the mouse. Am J Physiol Heart Circ Physiol 289: H455- H465, 2005.

LAMBERT MI, NOAKES TD: Spontaneous running increases VO2max and running performance in rats. $J$ Appl Physiol 68: 400-403, 1990.

LIVAK KJ, SCHMITTGEN TD: Analysis of relative gene expression data using real-time quantitative PCR and the 2(-Delta Delta C(T)) Method. Methods 25: 402-408, 2001.

NATALI AJ, WILSON LA, PECKHAM M, TURNER DL, HARRISON SM, WHITE E: Different regional effects of voluntary exercise on the mechanical and electrical properties of rat ventricular myocytes. $J$ Physiol 541: 863$875,2002$.

NELSON AJ, JURASKA JM, MUSCH TI, IWAMOTO GA: Neuroplastic adaptations to exercise: neuronal remodeling in cardiorespiratory and locomotor areas. J Appl Physiol 99: 2312-2322, 2005.

OVERTON JM, TIPTON CM, MATTHES RD, LEININGER JR: Voluntary exercise and its effects on young SHR and stroke-prone hypertensive rats. J Appl Physiol 61: 318-324, 1986.

PASSONNEAU JV, LAUDERDALE VR: A comparison of three methods of glycogen measurement in tissues. Anal Biochem 60: 405-412, 1974.

PFEIFER PC, MUSCH TI, MCALLISTER RM: Skeletal muscle oxidative capacity and exercise tolerance in rats with heart failure. Med Sci Sports Exerc 33: 542-548, 2001.

PINA IL, APSTEIN CS, BALADY GJ, BELARDINELLI R, CHAITMAN BR, DUSCHA BD, FLETCHER BJ, FLEG JL, MYERS JN, SULLIVAN MJ: Exercise and heart failure: A statement from the American Heart Association Committee on exercise, rehabilitation, and prevention. Circulation 107: 1210-1225, 2003.

RODNICK KJ, REAVEN GM, HASKELL WL, SIMS CR, MONDON CE: Variations in running activity and enzymatic adaptations in voluntary running rats. J Appl Physiol 66: 1250-1257, 1989.

SCHLUTER KD, SCHRECKENBERG R, DA COSTA REBELO RM: Interaction between exercise and hypertension in spontaneously hypertensive rats: a meta-analysis of experimental studies. Hypertens Res 33: 1155-1161, 2010.

SCHULTZ RL, SWALLOW JG, WATERS RP, KUZMAN JA, REDETZKE RA, SAID S, DE ESCOBAR GM, GERDES AM: Effects of excessive long-term exercise on cardiac function and myocyte remodeling in hypertensive heart failure rats. Hypertension 50: 410-416, 2007.

SIU PM, DONLEY DA, BRYNER RW, ALWAY SE: Citrate synthase expression and enzyme activity after endurance training in cardiac and skeletal muscles. J Appl Physiol 94: 555-560, 2003.

SMART N, MARWICK TH: Exercise training for patients with heart failure: a systematic review of factors that improve mortality and morbidity. Am J Med 116: 693-706, 2004.

SRERE PA, JOHN ML: Citrate synthase: [EC 4.1.3.7. Citrate oxaloacetate-lyase(CoA-acetylating)]. In: Methods in Enzymology. Academic Press, New York, NY, 1969.

SWALLOW JG, CARTER PA, GARLAND T JR: Artificial selection for increased wheel-running behavior in house mice. Behav Genet 28: 227-237, 1998a. 
SWALLOW JG, GARLAND T JR, CARTER PA, ZHAN WZ, SIECK GC: Effects of voluntary activity and genetic selection on aerobic capacity in house mice (Mus domesticus). $J$ Appl Physiol 84: 69-76, $1998 \mathrm{~b}$.

SWALLOW JG, KOTEJA P, CARTER PA, GARLAND T: Artificial selection for increased wheel-running activity in house mice results in decreased body mass at maturity. $J$ Exp Biol 202: 2513-2520, 1999.

SWALLOW JG, KOTEJA P, CARTER PA, GARLAND T JR: Food consumption and body composition in mice selected for high wheel-running activity. J Comp Physiol B 171: 651-659, 2001.

TERADA S, TABATA I, HIGUCHI M: Effect of high-intensity intermittent swimming training on fatty acid oxidation enzyme activity in rat skeletal muscle. Jpn J Physiol 54: 47-52, 2004.

VAN DEEL ED, DE BOER M, KUSTER DW, BOONTJE NM, HOLEMANS P, SIPIDO KR, VAN DER VELDEN J, DUNCKER DJ: Exercise training does not improve cardiac function in compensated or decompensated left ventricular hypertrophy induced by aortic stenosis. J Mol Cell Cardiol 50: 1017-1025, 2011.

VENTURA-CLAPIER R, METTAUER B, BIGARD X: Beneficial effects of endurance training on cardiac and skeletal muscle energy metabolism in heart failure. Cardiovasc Res 73: 10-18, 2007. 